\title{
APRESENTAÇÃO
}

Sebastião RODRIGUES-MOURA ${ }^{1}$

Graciella WATANABE ${ }^{2}$

Fábio PERBONI ${ }^{3}$

\section{Educação, Currículo e Ensino de Ciências: por uma base comum}

Considerando a complexidade da educação brasileira frente às (trans)formações sociais e o nível de exigência educacional impostos pela sociedade contemporânea, estimular o desenvolvimento de atividades comuns curriculares, a popularização da ciência e o êxito escolar têm se tornado elementos importantes de confluências para se constituir uma base nacional comum que possa atender as demandas educacionais emergentes. Por um lado, esta demanda possui direcionamentos para uma práxis pedagógica fortalecida, como forma de aprimoramento da ação docente, com vistas ao engajamento dos estudantes, à autonomia da aprendizagem e à formação de estudantes crítico-reflexivos em uma sociedade globalizada.

O Dossiê "O Ensino de Ciências e a Base Nacional Comum Curricular (BNCC)" emergiu a partir das motivações de dois professores-pesquisadores da temática, planejado como forma de incorporar diferentes visões sobre a proposta curricular brasileira, instituída entre tantas demandas e polêmicas que a contextualizaram, desde a elaboração da sua primeira versão até a homologação da versão final em 2018.

Diante dos desafios impostos aos professores, gestores e, principalmente, aos alunos da educação básica no país, pesquisadores e profissionais da Educação em Ciências aceitaram o desafio de colaborarem com reflexões acerca de impactos, críticas e análises da BNCC no ensino de ciências. Nesse sentido, foram recebidos vários artigos com diversidade institucional e regional do país, assim como os pareceristas convidados com expertise na temática, que contribuíram para a consolidação deste dossiê que apresentamos para vocês na Horizontes: Revista de Educação.

\footnotetext{
${ }^{1}$ Editor especial do dossiê "O Ensino de Ciências e a Base Nacional Comum Curricular (BNCC)". É professor do Instituto Federal de Educação, Ciência e Tecnologia do Pará (IFPA) e vice-coordenador do Grupo de Pesquisa em Rede para o Ensino de Física (GePREF). E-mail: sebastiao.moura@ifpa.edu.br

${ }^{2}$ Editora especial do dossiê "O Ensino de Ciências e a Base Nacional Comum Curricular (BNCC)". É professora do Centro de Ciências Naturais e Humanas (CCNH) da Universidade Federal do ABC (UFABC) e coordenadora do grupo de pesquisa Desigualdade Educacional, Ciência e Democracia (DECiDe). E-mail: graciella.watanabe@ufabc.edu.br

${ }^{3}$ Editor da Horizontes: Revista de Educação. Professor da Universidade Federal de Grande Dourados (UFGD).E-mail: fabio.perboni@ufgd.br
} 
Organizamos o dossiê em três blocos: críticas/análises, propostas e implementação. No primeiro, temos um conjunto de artigos que apresentam as críticas e análises conceituais sobre a BNCC.

Para Ricardo Desidério a crítica concentra-se no silenciamento e exclusão do tema sexualidade no documento da BNCC. Autor do artigo "A exclusão da temática sexualidade nos anos iniciais do ensino fundamental na BNCC e seus reflexos para o ensino de ciências" chama a atenção para os problemas dessa ausência na formação dos alunos dos anos iniciais do Ensino Fundamental, de forma a elencar algumas reflexões e trazer evidências necessárias para um trabalho efetivo e sistemático.

O trabalho dos pesquisadores Felipe Muneratto, Rodolfo Henrique de Souza, Matheus Ianello, Diego Nunes Navarro e Graciella Watanabe tem como interesse a questão da trajetória social do grupo que produziu a BNCC, sendo fonte de estudo no artigo "A constituição do grupo de elaboração da BNCC de Ensino de Ciências: trajetórias de seus atores sociais e seus impactos na elaboração da proposta", desvelando as trajetórias históricas e sociais dos atores no campo científico e universitário, como forma de compreensão dos impactos associados para a elaboração da BNCC.

As pesquisadoras Cassiane Beatrís Pasuck Benassi, Mariane Grando Ferreira e Dulce Maria Strieder apresentam um debate no artigo "A Base Nacional Comum Curricular (BNCC) e a epistemologia de Paul Karl Feyerabend no ensino de ciências: questões terminológicas", no qual analisam o documento e encontram consonâncias entre a teoria de Feyrabend e as habilidades e competências que o compõem, principalmente no que se fundamentam as disciplinas de Ciências Natureza e suas Tecnologias (Física, Química e Biologia) no ensino médio.

No segundo bloco, referente às propostas, sejam de reflexões teóricas como práticas para a formação docente e discente, temos o artigo dos pesquisadores Sebastião RodriguesMoura e Terezinha Valim Oliver Gonçalves intitulado "Por uma cultura científica para a incorporação social da ciência: implicações curriculares na $B N C C^{\prime \prime}$ que busca compreender como a cultura científica está se constituindo e se difundindo, de modo a permitir ao aluno uma formação para desenvolver a autonomia, a criticidade e a incorporação social da produção científica.

No artigo intitulado "Um desafio para a Base Nacional Comum Curricular: o diálogo entre a alfabetização científica e tecnológica e a inclusão educacional" a pesquisadora Paloma Alinne Alves Rodrigues busca mobilizar o debate da inclusão e apresentar projeto de extensão que visa produzir sequências didáticas inclusivas no âmbito da formação de licenciandos com vista aos pressupostos teóricos da BNCC.

Já no grupo de implementação, há confluências práticas de ações pedagógicas para a sala de aula. No artigo "O ensino de ciências nos anos iniciais do ensino fundamental: uma proposta metodológica a partir da BNCC" dos pesquisadores Cristiane Talita Gromann de Gouveia e Sérgio Candido de Gouveia Neto buscam propor metodologias por projetos que visem dar suporte para a formação do aluno dos anos iniciais em consonância ao debate da 


\section{HORIZONTES - REVISTA DE EDUCACATO}

e-ISSN: $2318-1540$

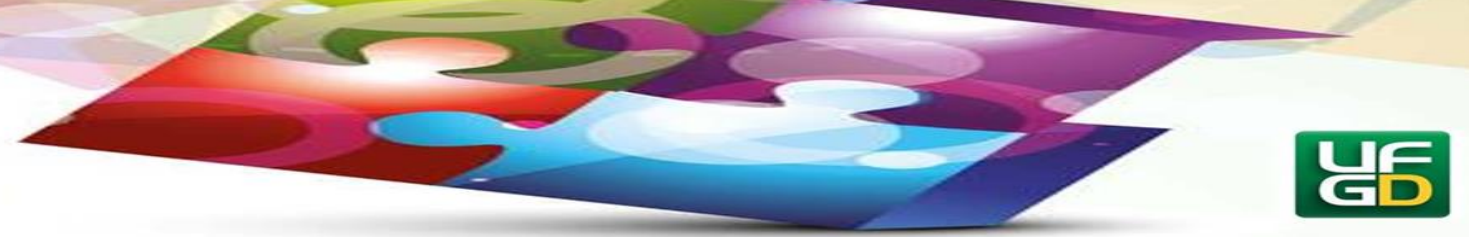

BNCC

Para as pesquisadoras Adriana Ramos Santos e Letícia Mendonça Lopes Ribeiro no artigo "A Base Nacional e suas implicações na proposta curricular de ciências naturais do Estado do Acre" a implementação do documento se coloca como o desafio para o fortalecimento da cultura local através da análise histórica e documental em seu Estado.

A partir desse conjunto de reflexões que perpassam propostas e teorias no âmbito acadêmico, o chão da sala de aula também é representado através de olhares para as implementações da BNCC em diferentes espaços educacionais. Para Leonardo Salvalaio Muline e Isabela Cabral Félix de Sousa no artigo "Práticas pedagógicas no ensino de ciências dos anos iniciais da educação fundamental de uma escola municipal de Vitória/ES" destaca-se o desafio imposto da BNCC que traz consigo complexidades da inserção das ciências nos anos iniciais do Ensino Fundamental. Discutem, assim, como o ensino por investigação ainda é um desafio a ser incorporado nesse contexto.

No artigo "Visão dos professores de ciências da rede municipal de Barra Mansa diante dos desafios da Base Nacional Comum Curricular", dos autores Lucas Peres Guimarães e Denise Leal de Castro, estão conduzidos estudos para leituras sobre como os docentes percebem a BNCC e os desafios que são apresentados em sua futura implementação.

Em linhas gerais, o dossiê ora apresentado, traz à luz as reflexões que estão sendo desenvolvidas por estudiosos da área, a fim de consolidar um (re)pensar para o Ensino de Ciências no Brasil, frente às orientações da BNCC. Buscou-se, desta forma, contribuir e subsidiar com indicadores educacionais para promover discussões teórico-práticas que possam guiar o processo de ensino-aprendizagem de Ciências da Natureza e suas Tecnologias, no percurso da Educação Básica, além de colaborar com a literatura frente às possibilidades de críticas/análises, propostas e implementação da BNCC.

\section{Artigos - Fluxo Contínuo}

Apresentamos ainda nesta edição mais oito artigos submetidos em fluxo contínuo da Horizontes - Revista de Educação. O primeiro texto, apresentado em espanhol, foi escrito por José Manuel Silvero ARÉVALOS, Mariza Amaral MACIEL, pesquisadores do Paraguai, que analisaram de que maneira o normalismo como corrente pedagógica foi inserido na educação paraguaia em sintonia com as ideais higienistas e positivistas que influenciaram a configuração social e política de um país, no texto intitulado "Notas en torno a la "suciedad" y al "normalismo" en laeducación paraguaya".

$\mathrm{Na}$ sequencia o texto "Possibilidades contributivas do ensino desenvolvimental para a problemática da falta de atenção dos alunos nas aulas de educação física no ensino fundamental, escrito por Silas Alberto GARCIA, Made Júnior MIRANDA, Katianny Santana Lúcio da COSTA, Rodrigo Pereira de SOUSA e Samuel Gomes de SOUZA, analisa as causas da desatenção dos alunos nas aulas de Educação Física no ensino fundamental de uma escola pública do município de Goiânia. 


\section{HORIZONTES - REVISTA DE EDUCACATO}

e-ISSN: $2318-1540$

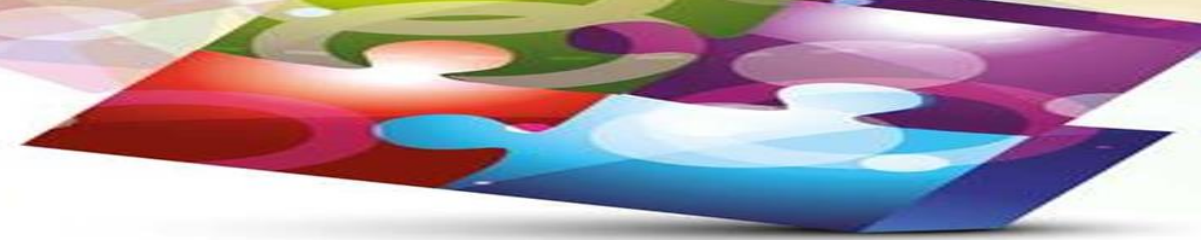

O Terceiro texto de Ana Claudia Lemes de MORAIS, intitulado "A busca por uma versão para o início da licenciatura em matemática a distância da UFMS: do embarque ao desembarque" se debruça sobre uma análise de um curso à distância com foco na Licenciatura em Matemática da UFMS. Na sequência Nilson Francisco da SILVA e Maria Alice de Miranda ARANDA se debruçam sobre a gestão democrática na educação com o texto "Participação e gestão democrática da educação: o legislado é o praticado?

Analisando a formação de professores, com foco na temática da Educação Especial nos cursos de licenciatura temos o texto de Mylena Freitas ARAÚJO e Andréia Nunes MILITÃO, denominado "Formação de professores para a educação especial: análise dos Projetos Pedagógicos dos Cursos de Licenciatura da Universidade Federal da Grande Dourados"

Patrícia Cavalcante RODRIGUES, John Lee Silva PEREIRA, Natália Cristina de Oliveira Vargas e SILVA, com o texto "Percepção das praticantes sobre os benefícios físicos e psicológicos da dança do ventre" discutem os benefícios desta prática a partir da percepção de seus praticantes.

Investigando a institucionalização do Ensino à distância esta edição traz o texto intitulado "O processo de institucionalização da Ead na UFG a partir da experiência com a Universidade Aberta do Brasil", escrito por Lilian Ucker PEROTTO e Marília de GOYAZ. Por fim o último texto desta seção escrito por Andréia Pires Dias CLARO, Eduardo Adão RIBEIRO e Washington Cesar Shoiti NOZU, trata de compreender a organização e o funcionamento das classes hospitalares, no texto Organização e funcionamento das classes hospitalares: uma prerrogativa da educação especial?"

\section{Resenhas e Relatos de Experiencia}

Esta edição traz ainda mais seis textos, sendo uma resenha e cinco relatos de experiencia. Proporcionando aos leitores uma variedade de conhecimentos e perspectivas sobre diferentes questões educacionais.

Joilson Silva de SOUSA, Alanderson Maxson Ferreira do NASCIMENTO e Avelino Aldo de LIMA NETO apresentam a resnha do livro SOUSA, Antônia de Abreu; OLIVEIRA, Elenice Gomes de. (Org.). Educação Profissional:análise contextualizada. Fortaleza: Edições UFC, 2014. Contribuindo para a reflexão sobre a educação e trabalho.

Seguem ainda os relatos de experiência sobre o ensino de artes elaborado por Ana Maria Ricci MOLINA e Roberta Ricci MOLINA, com o título de "O ensino de artes e a busca pela autonomia de estudantes em processo de criação em sala de aula".

$\mathrm{Na}$ sequencia o texto "Programa de acompanhamento escolar da rede municipal de ensino de Dourados-MS: um relato de experiência", escrito por Clair Moron dos Santos MUNHOZ, Cristina Fátima Pires Ávila SANTANA, Mariolinda Rosa Romera FERRAZ, Elis Regina dos Santos VIEGAS relata a experiência do Programa de Acompanhamento Escolar (PAE) que se configurou em atendimento à criança com dificuldade de aprendizagem no 


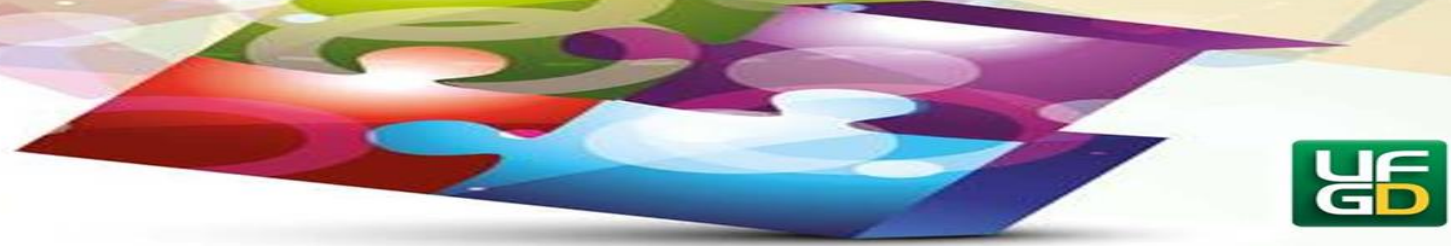

processo de alfabetização e em formação continuada com os profissionais alfabetizadores da Rede Municipal de Ensino de Dourados-MS.

Tratando da formação continuada de professores de matemática o texto de Adriana Vilela BISCARO, Vanderlea Rodrigues BAZÃO, Ana Maria Villela GRECCO e Sandra Regina Oliveira SOUZA, foi denominado de "Formação continuada de professores de matemática: um relato de experiência sobre o projeto PAPMEM".

O texto "Reflexão sobre uma prática pedagógica em matemática: um relato de experiência" de Carlos Rodrigues de CARVALHO, trata um relato de atividades que foram desenvolvidas no ensino da Matemática, com alunos do $2^{\circ}$ ano do Ensino Médio da cidade de Parambu-CE.

Por fim o texto "Relato de experiência do uso das TDICS para produção de mídias no ensino fundamental" escrito por Anderson Pedro LAURINDO, Priscila Sirigate APLEWICZ, Josie Ágatha Parrilha da SILVA e Eloisa Aparecida Silva Ávila de MATOS trata do uso das novas tecnologias para ensinar e aprender. numa reflexão sobre a eminente necessidade de reduzir a distância entre escola e o cotidiano do aluno através do uso das Tecnologias Digitais de Informação e Comunicação (TDIC). 